\title{
Evaluation and Comparison of the Marginal Adaptation of an Epoxy, Calcium Hydroxide-based, and Bioceramic-based Root Canal Sealer to Root Dentin by SEM Analysis: An In Vitro Study
}

\author{
Asha Pius $^{1}$, Jain Mathew ${ }^{2}$, Robin Theruvil ${ }^{3}$, Saira George ${ }^{4}$, Midhun Paul ${ }^{5}$, Allu Baby ${ }^{6}$, John Jacob ${ }^{7}$
}

\begin{abstract}
Aim: The aim of this study is to evaluate and compare the sealer penetrability and gap formation of root canal sealer to root dentin filled with AH Plus, Sealapex, and BioRoot RCS.

Materials and methods: Twenty-seven mandibular second premolars were selected and were radiographed at two angulations. The teeth were stored in labeled plastic vials containing artificial saliva and were randomly assigned to three groups based on the sealer, group I-AH Plus $(n=9)$, group II-Sealapex $(n=9)$, and group III-BioRoot RCS $(n=9)$; teeth were de-coronated and the conventional root canal therapy was done with Protaper gold rotary files. Three groups were filled with AH Plus, Sealapex, and BioRoot RCS with the single-cone technique. About 1-mm sections of apical, middle, and cervical third were taken using a water-cooled low-speed saw. All specimens are evaluated using a scanning electron microscope.

Clinical significance:The main goal of obturation is to provide a three-dimensional seal, thereby preventing the reinfection of the root canal and preserving the health of periapical tissues. Because of the hydrophobic nature of gutta-percha, the sealer tends to pull away from gutta-percha on the setting. To overcome these drawbacks, new sealer systems have been introduced to enhance the sealing ability. Resin-based sealers have gained more popularity in recent years because these sealers penetrate deep into the dentinal tubules due to their better flowability, long setting time, and provide long-term dimensional stability. The resin-based sealer used in this study is the AH Plus. It is compared with the newly introduced bioceramic sealer BioRoot RCS for marginal adaptation.

Results: It was found that the AH Plus group had a higher depth of sealer penetration than other groups and the BioRoot RCS group revealed a minimum gap formation than other groups of sealers evaluated in the study.

Conclusion: The Bioceramic sealer revealed better sealer penetrability at the apical third and minimal gap formation compared to the epoxy resin-based and the calcium hydroxide-based sealer.
\end{abstract}

Keywords: Bioceramic sealer, Gap formation, Marginal adaptation, Sealer penetrability.

Conservative Dentistry and Endodontic Journal (2019): 10.5005/jp-journals-10048-0046

\section{INTRODUCTION}

The three-dimensional obturation of the root canal system is widely accepted as one of the major factors for the success of endodontic treatment. A wide variety of materials are available for root canal obturation; however, the gutta-percha cones along with the sealer remain the most accepted material of choice. Different types of sealers have been used in conjunction with gutta-percha for root canal obturation.

Because of the hydrophobic nature of gutta-percha, the sealer tends to pull away from gutta-percha on the setting. To overcome these drawbacks, new sealer systems have been introduced to enhance the sealing ability. ${ }^{1}$

The root canal sealer should be capable of creating an effective bond to the core material and the dentin of the root canal to prevent microleakage at the interface. ${ }^{1}$ Epoxy resin-based sealers have shown good physiochemical properties as well as excellent apical sealing. The AH Plus is an epoxy-bisphenol resin-based sealer that also contains adamantine and bonds to root canal. ${ }^{2}$

Bioceramics are inorganic, nonmetallic, and biocompatible materials that have mechanical properties similar to dental hard tissues. They are chemically stable, noncorrosive, and interact well

\footnotetext{
${ }^{1-7}$ Department of Conservative Dentistry and Endodontics, St. Gregorios Dental College, Ernakulam, Kerala, India
}

Corresponding Author: Asha Pius, Department of Conservative Dentistry and Endodontics, St. Gregorios Dental College, Ernakulam, Kerala, India, Phone: +91 9446747772, e-mail: ashapius123@gmail. com

How to cite this article: Pius A, Mathew J, et al. Evaluation and Comparison of the Marginal Adaptation of an Epoxy, Calcium Hydroxidebased, and Bioceramic-based Root Canal Sealer to Root Dentin by SEM Analysis: An In Vitro Study. Cons Dent Endod J 2019;4(1):6-13.

Source of support: Nil

Conflict of interest: None

with the organic tissue. Newer bioceramic sealers possess very high bond strength with dentin walls by the formation of hydroxyapatite crystals. $^{3}$

According to Erickson, penetration of root canal sealers into dentinal tubules is essential to achieve a good bond strength. The stability of the bond formed between the root dentin and the gutta-percha interface reduced the failure associated with leakage 
of the material. Traditionally, endodontic sealers based on zinc oxide eugenol (ZOE) were used, but the major disadvantage with the above sealers was the poor sealing efficacy and bonding ability to the core material and canal wall. Various modifications have been made in the sealer chemistry and formulation to improve the penetration and bond strength of sealers. ${ }^{4}$

The present in vitro study was conducted to evaluate and compare the marginal adaptation of bioceramic-based (BioRoot RCS), calcium hydroxide-based (Sealapex), and epoxy resin-based (AH Plus) sealers.

\section{Materials and Methods Sample Collection}

Twenty-seven non-carious, intact, freshly extracted mandibular premolar teeth with a single root and a single canal were collected (Fig. 1). Teeth with root fractures, root caries, evidence of periapical resorptive processes, or multiple canals were excluded from the study. A preoperative radiograph was taken in two different angulations to assess the presence of a single canal, and the teeth presented with a variation were discarded. Twenty-seven selected teeth were then stored in artificial saliva.

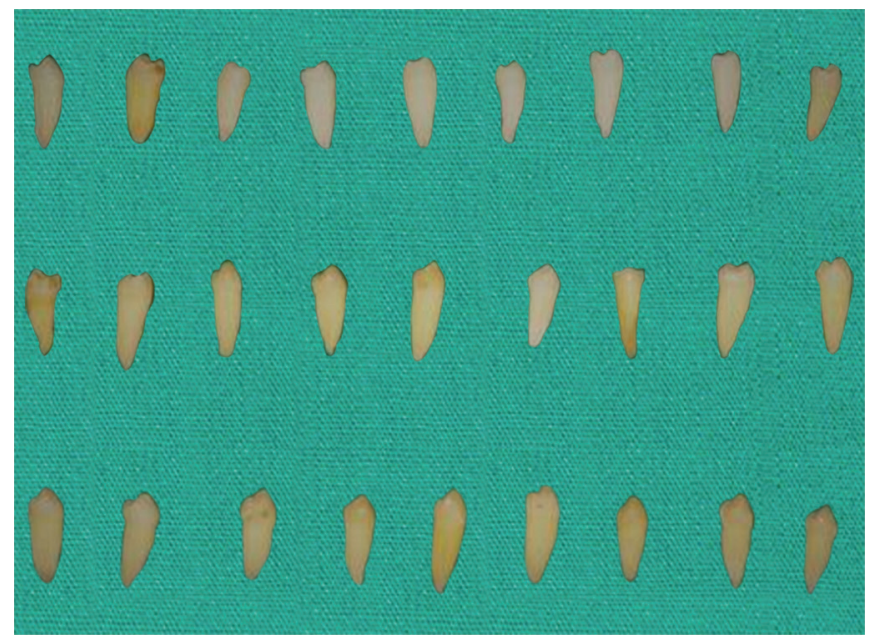

Fig. 1: Sample collection

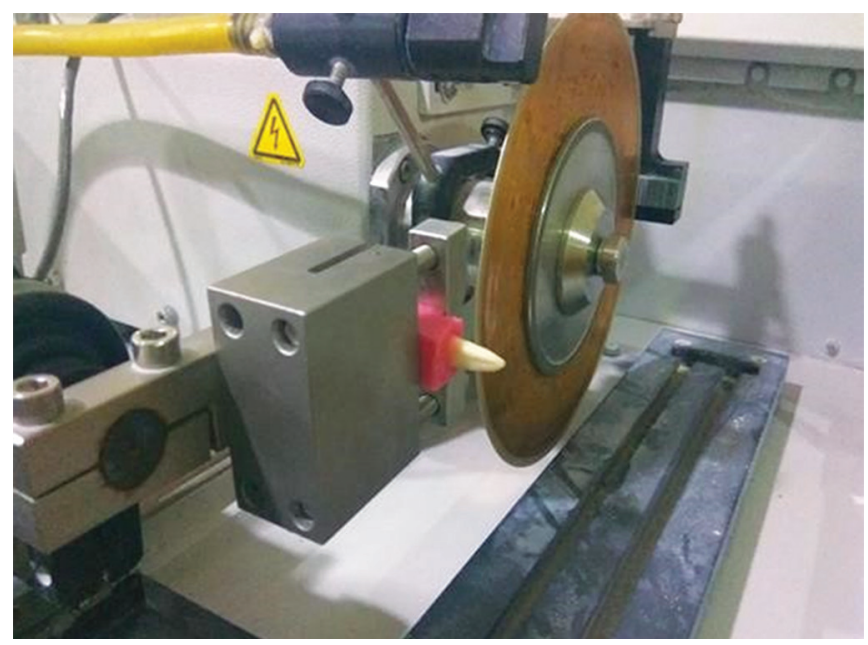

Fig. 3: Sectioning of samples

\section{Root Canal Preparation}

Conventional access cavities were made (endo access bur, Dentsply), followed by irrigation with $5 \mathrm{~mL} 5.25 \% \mathrm{NaOCl}$. A working length was established $0.5 \mathrm{~mm}$ short of the apical foramen. Protaper gold instruments were activated in pecking motion driven with the xmart (Dentsply). The instruments were moved in the apical direction using an in-and-out pecking with a light apical pressure, being cleaned after three pecking motions. Canals were irrigated with $5.25 \% \mathrm{NaOCl}$ between each preparation step. Canals were enlarged up to a file size of F2. At the end of preparation, the canals were flushed with $17 \%$ EDTA followed by $5.25 \% \mathrm{NaOCl}$ irrigation and, finally, rinsed with saline. In each group, the canals were divided into three subgroups with nine samples each filled with AH Plus, filled with Sealapex, and filled with BioRoot RCS using the single-cone technique.

The tooth is then mounted on acrylic stumps (Fig. 2) and 1-mm thin serial sections of the tooth are made using a water-cooled lowspeed saw (Buehler Isomet 1000) (Figs 3 and 4).

For assessment of gaps, the slices were dehydrated in an ascending ethanol series.

For assessment of sealer penetrability, the slices were subjected to demineralization with hydrochloric acid $6 \mathrm{~mol} / \mathrm{L}$ followed by deprotenization in $2.5 \% \mathrm{NaOCl}$.

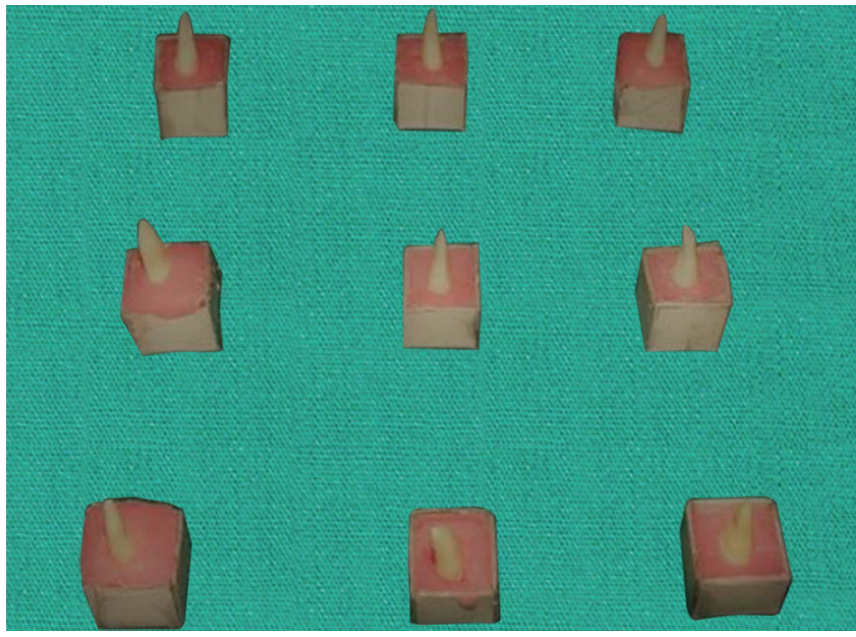

Fig. 2: Samples mounted in acrylic blocks

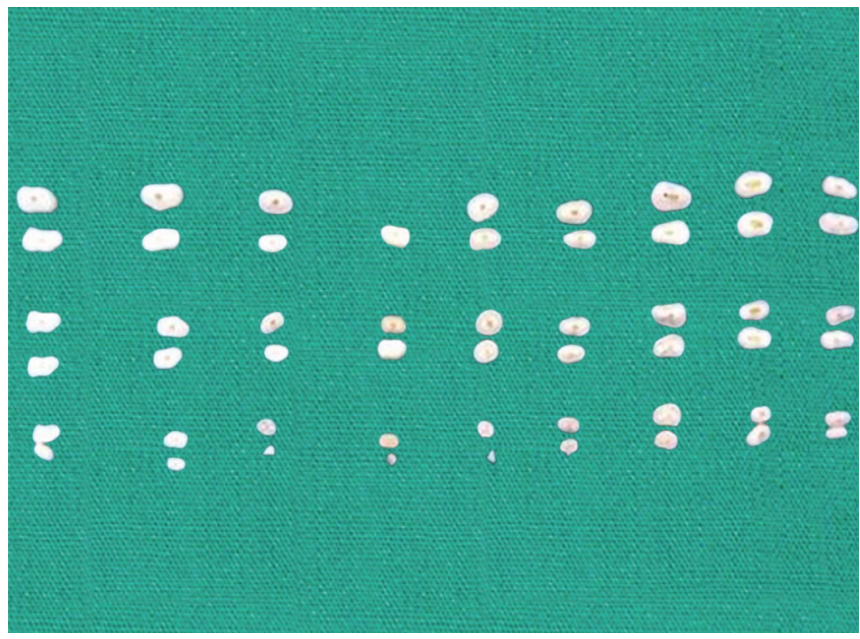

Fig. 4: 1-mm serial sections 


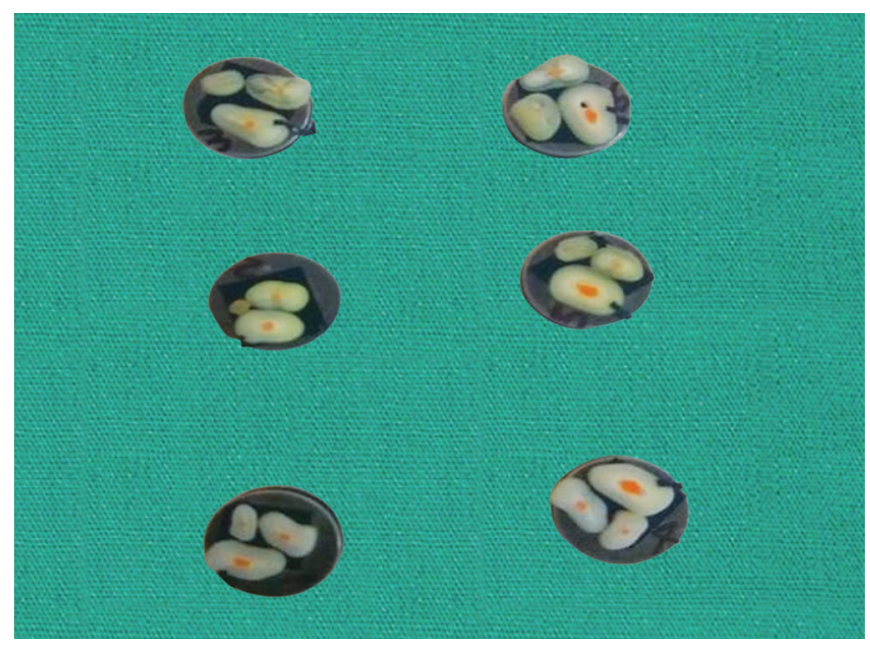

Fig. 5: Mounting of samples

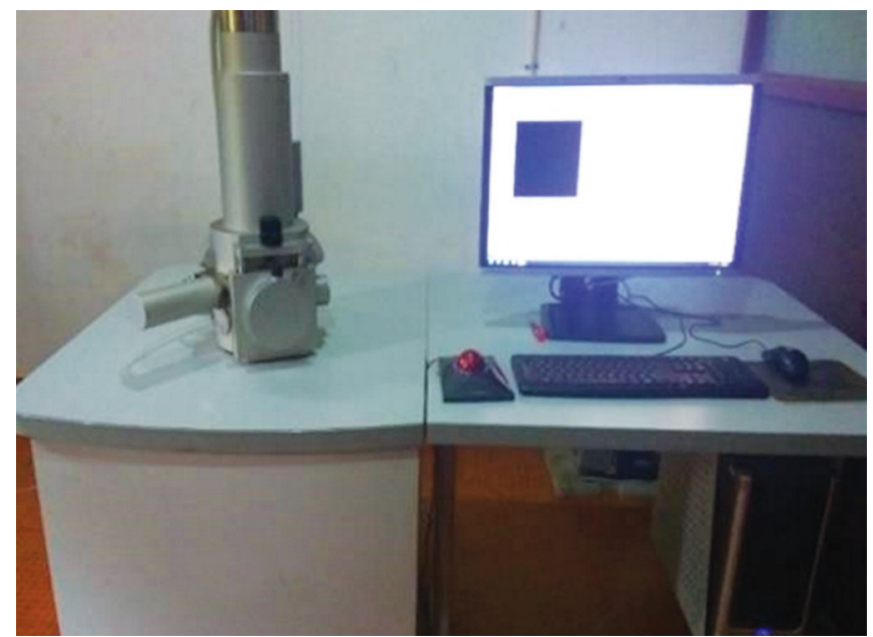

Fig. 7: SEM analysis

All specimens were sputter coated with gold-palladium and viewed with a scanning electron microscope (Figs 5 to 7).

Scanning electron microscopy (SEM) images of apical, middle, and cervical sections for sealer penetrability and gap formation in all the three groups are presented in Figures 8 and 9.

- Assessment of sealer penetrability

- The maximum depth of sealer penetration = Distance from sealer/gutta-percha interface to the highest depth of sealer penetration to root dentin

- Assessment of gaps

- Gap formation = Distance from sealer to root dentin interface values were calculated in micrometers.

\section{Statistical Analysis}

This study deals with testing whether there is any significant difference in the mean value of sealer penetrability and gap formation among three different materials. One-way analysis of variance (ANOVA) is used for the analysis. In all the analysis, the significance level is taken to be 0.05 (i.e., if the $p$ value is less than 0.05 , then reject the null hypothesis or it can be concluded that the null hypothesis is statistically significant) and the tests are two-tailed. The statistical analysis was carried out using the statistical package, SPSS (version 22.0.0.0). Post hoc was

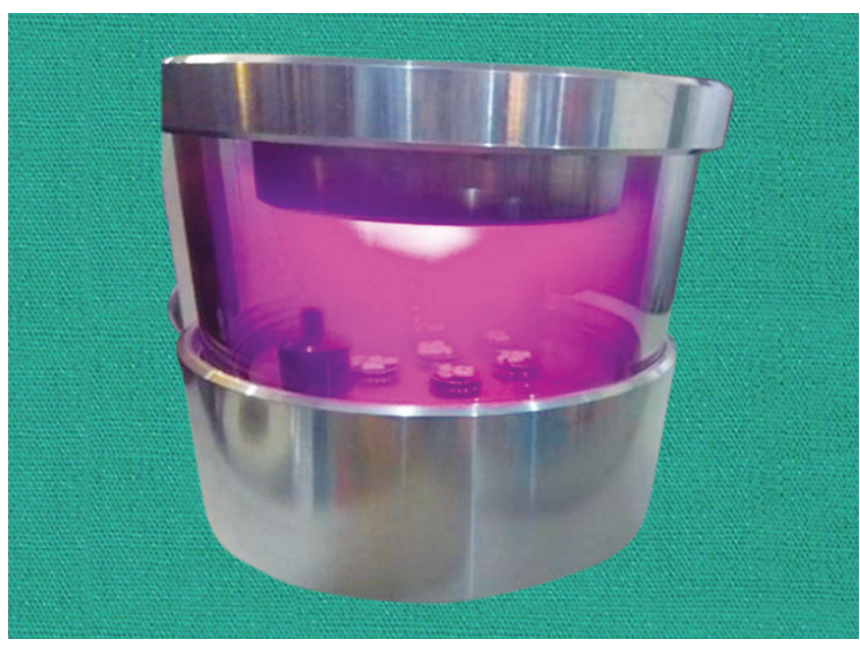

Fig. 6: Sputter coating

conducted since there was a significant difference among the groups. The data are tabulated in Tables 1 to 6 . A graphical representation of sealer penetrability and gap formation is represented in Figures 10 and 11 , respectively.

\section{Observations}

Sealer penetrability

Table 1: Descriptive statistics

\begin{tabular}{llrrlr}
\hline & & \multicolumn{1}{l}{ Mean } & Std. deviation & Std. error \\
\hline Apical & AH Plus & 9 & 106.588 & 25.545 & 8.515 \\
& BioRoot RCS & 9 & 131.110 & 34.865 & 11.622 \\
& Sealapex & 9 & 57.649 & 39.381 & 13.127 \\
& Total & 27 & 98.449 & 44.949 & 8.650 \\
Middle & AH Plus & 9 & 175.376 & 22.621 & 7.540 \\
& BioRoot RCS & 9 & 104.375 & 36.584 & 12.195 \\
& Sealapex & 9 & 95.723 & 44.490 & 14.830 \\
& Total & 27 & 125.158 & 50.006 & 9.624 \\
Cervical & AH Plus & 9 & 220.269 & 26.539 & 8.846 \\
& BioRoot RCS & 9 & 154.002 & 13.078 & 4.359 \\
& Sealapex & 9 & 52.344 & 47.502 & 15.834 \\
& Total & 27 & 139.205 & 76.561 & 14.734 \\
\hline
\end{tabular}

\section{Results}

The present study was conducted to compare and evaluate the penetrability and gap formation of three different sealers. The sealer penetration was estimated using scanning electron microscope images by calculating the distance from the sealer-gutta-percha interface to the root dentin in micrometers from each sample with $n=9$ with a magnification range of $1,500 \times-2,000 \times$. The mean and standard deviations were estimated from the samples with $n=9$ for each study group:

- Sealer penetrability-AH Plus $>$ BioRoot RCS $>$ Sealapex.

- Gap formation-BioRoot RCS $<$ AH Plus $<$ Sealapex.

\section{Discussion}

A fluid-tight seal is the main requisite to achieve a successful obturation. Several types of endodontic sealers have been recommended to achieve this goal which includes epoxy 


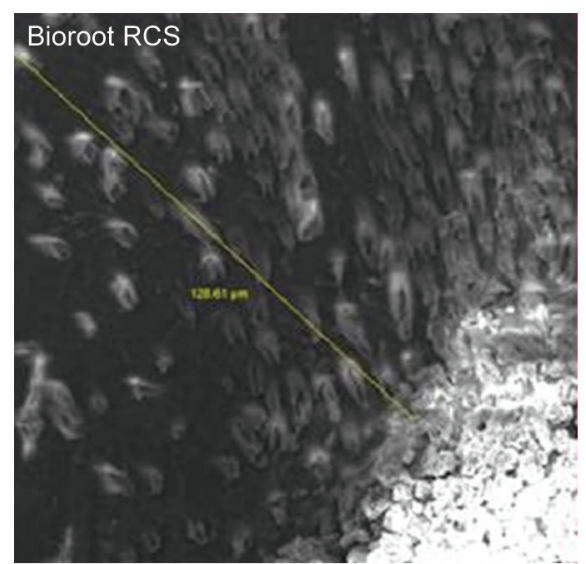

Apical

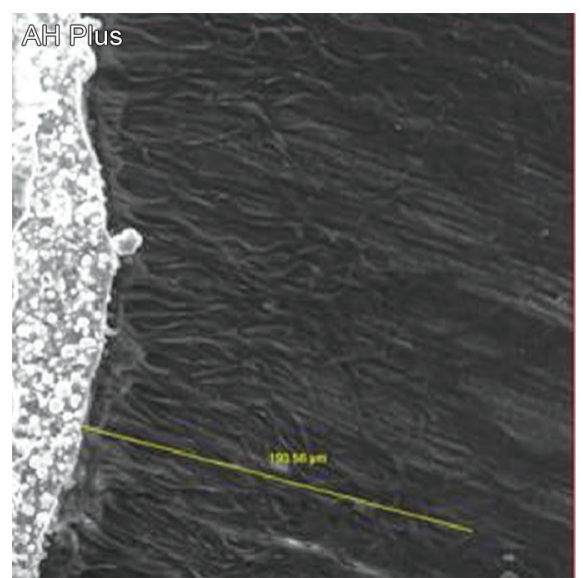

Apical

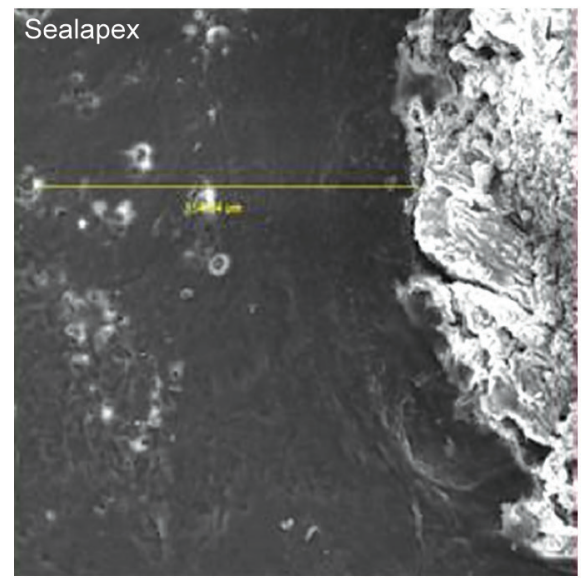

Apical

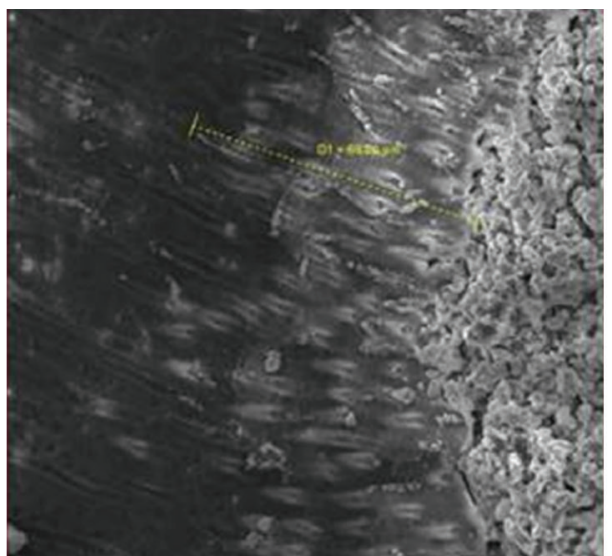

Middle

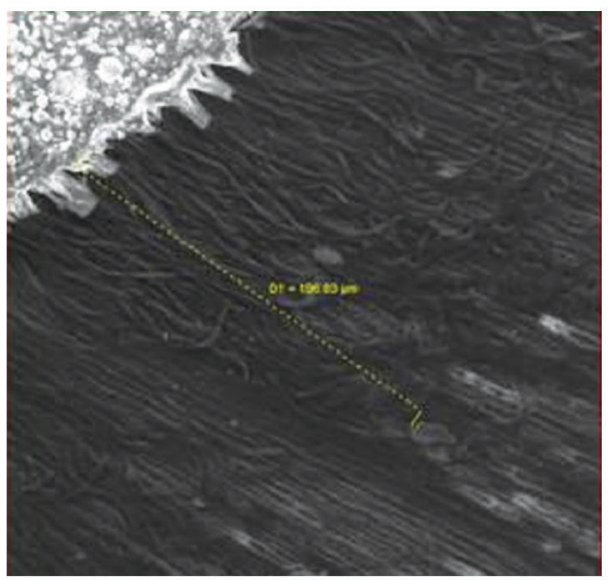

Middle

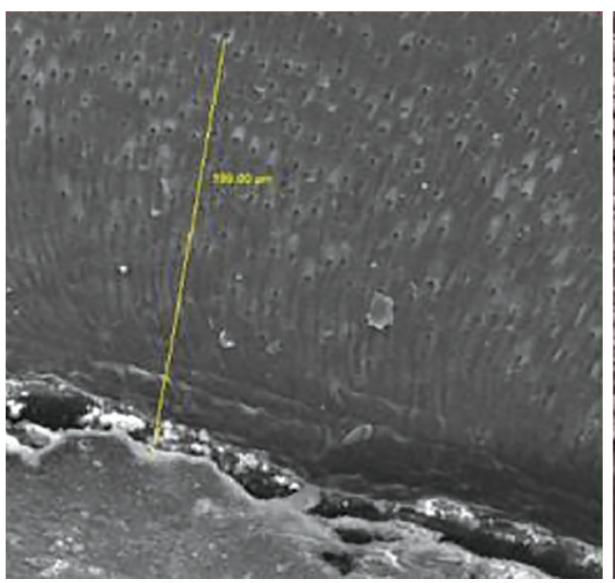

Middle

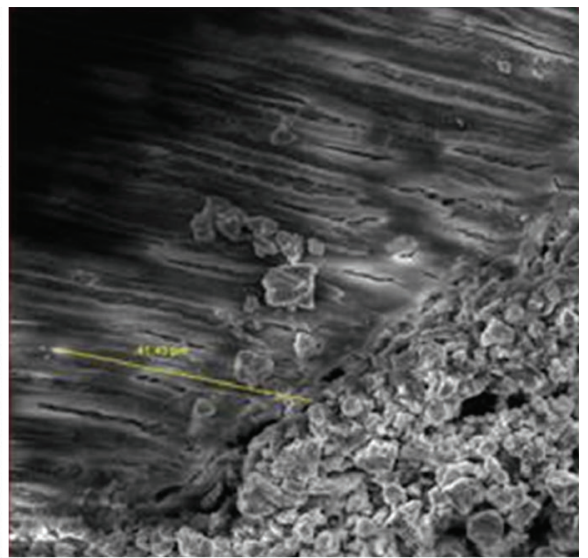

Cervical

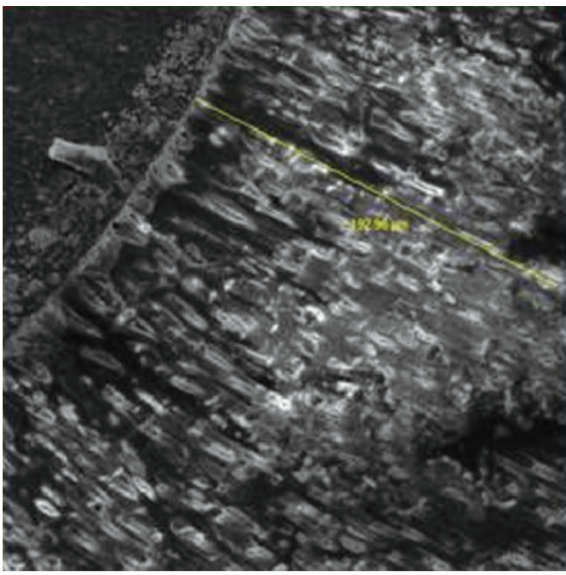

Cervical

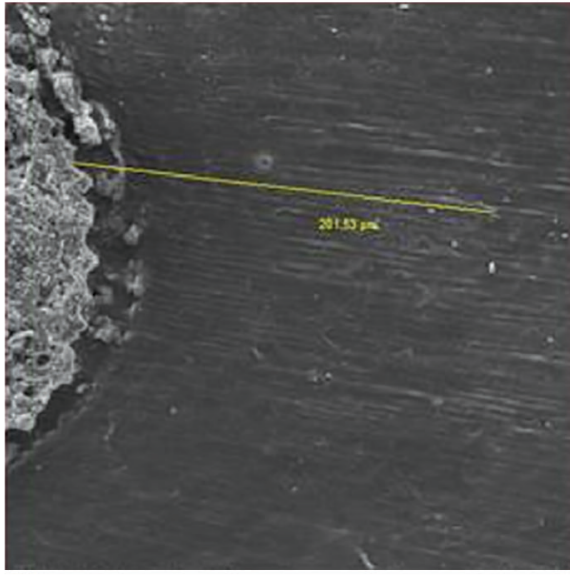

Cervical

Fig. 8: Scanning electron microscopy images of sealer penetrability

resin-based sealers, mineral trioxide aggregate-based sealer, calcium silicate-phosphate-based bioceramic sealer, and calcium hydroxide-based sealer. ${ }^{5}$

Among all the tested groups used in this study, the BioRoot RCS sealer was the best group which showed a greater penetrability at the apical third and minimal gap formation.

Better performance of the bioceramic sealer can be explained on the basis of its small particle size, hydrophilicity, and low contact angle which enable the cement to spread easily over the dentin walls of the root canal and get inside and fill the lateral micro-canals.
Bioceramic root canal sealers also exhibit chemical bonding to root canal dentin walls as well as its corresponding bioceramic particleimpregnated gutta-percha. ${ }^{6}$ It also exhibits a significant expansion of $0.20 \%$. These features result in a gap-free chemical bond between the sealer and dentinal walls, thus, making it an effective sealer. The Sealapex sealer differs from other root canal sealers in that it contains calcium hydroxide as a major constituent. The material has a very low setting shrinkage and low solubility in tissue fluids.

In the present study, the AH Plus had a good penetration at the cervical third than the middle and apical third because of its low 


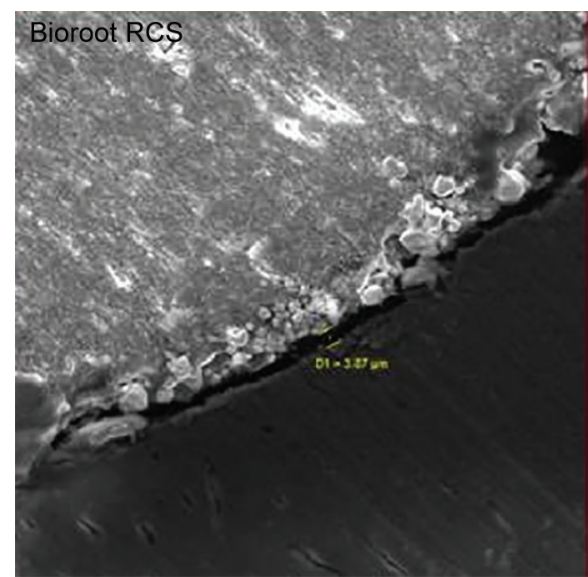

Apical

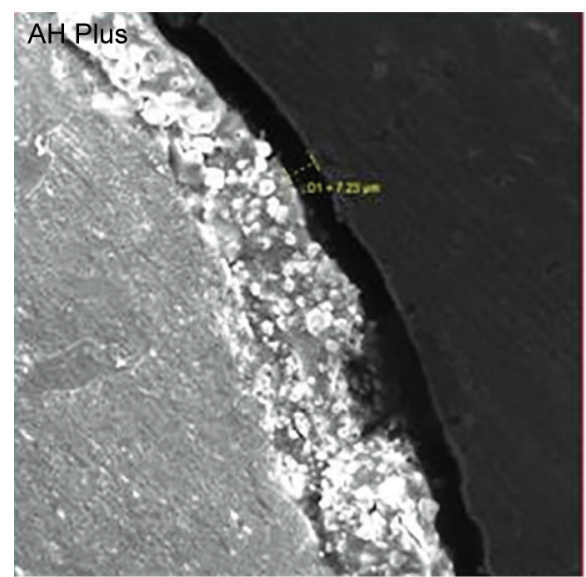

Apical

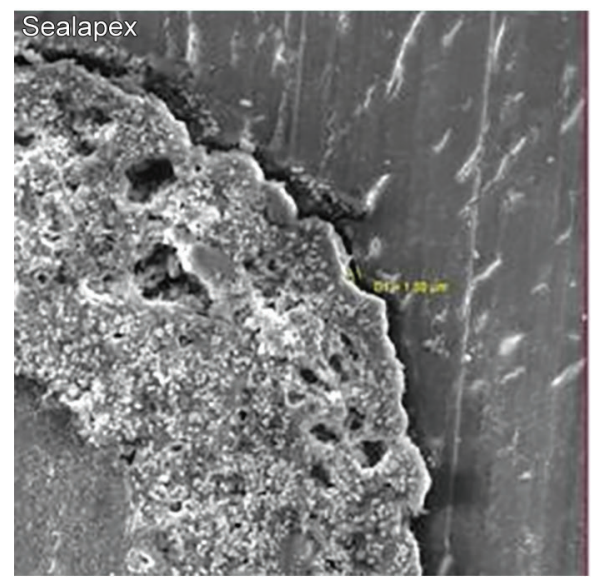

Apical

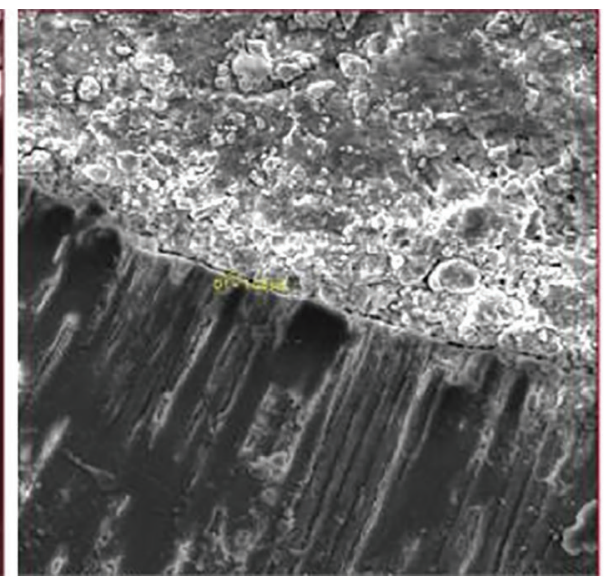

Middle

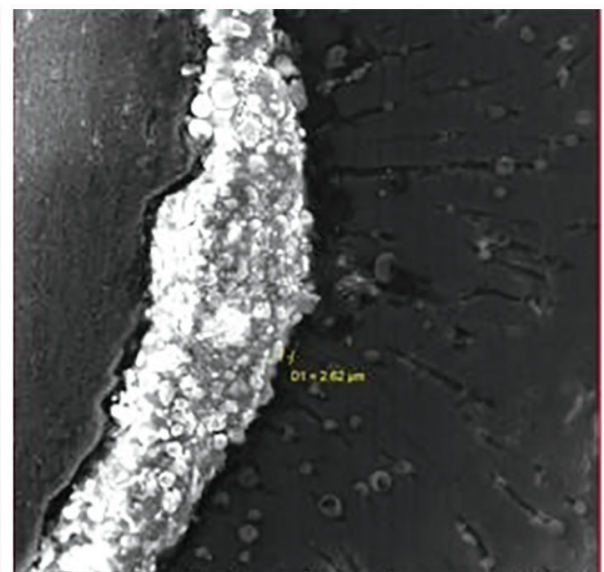

Middle

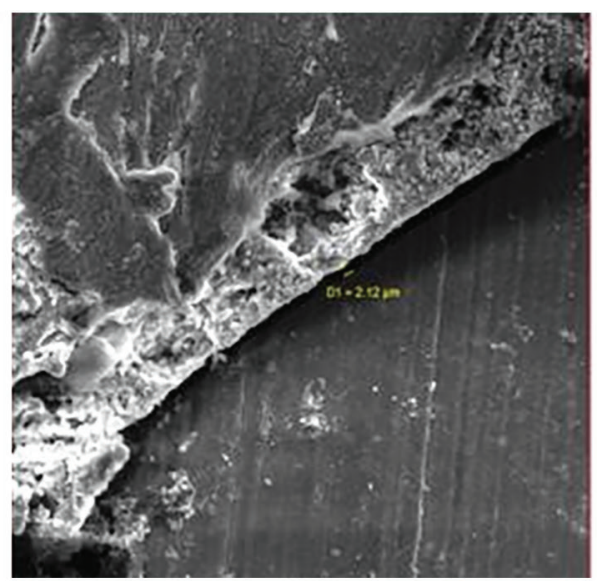

Middle

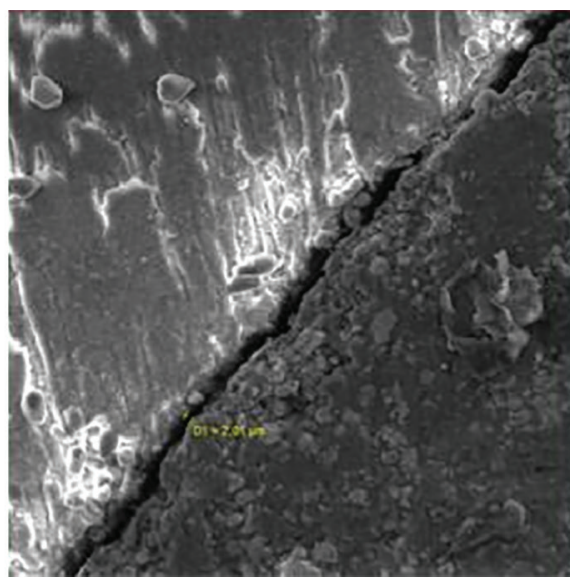

Cervical

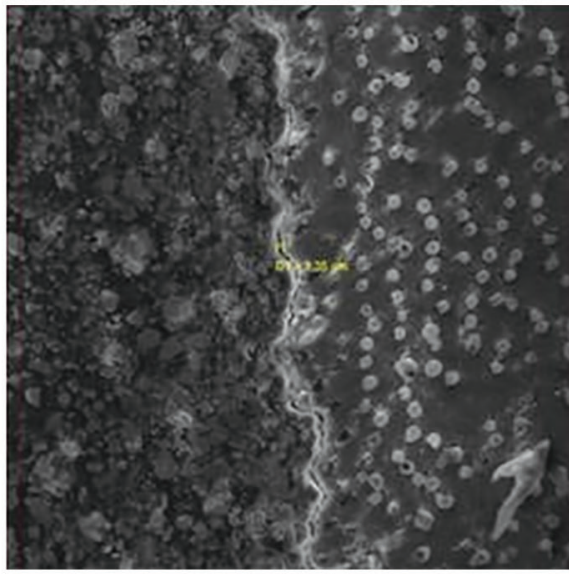

Cervical

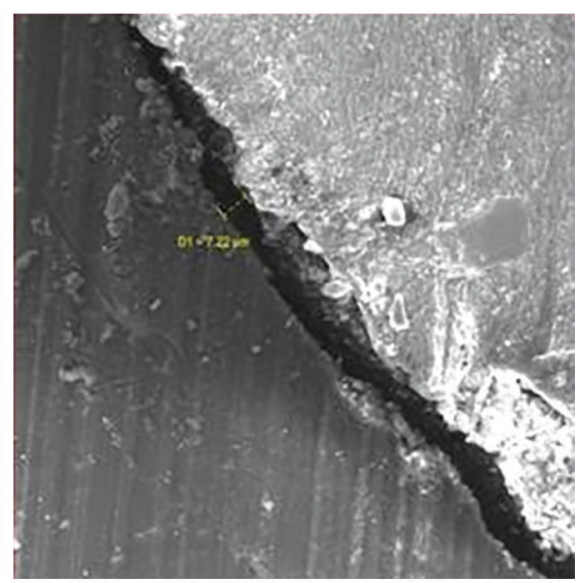

Cervical

Fig. 9: Scanning electron microscopy images of gap formation

particle size and film thickness which is in the range of $20-25 \mu \mathrm{m}$. The low solubility of AH Plus on exposure to tissue fluids aids in better penetration. The results of the present study were in agreement with the previous study conducted by Borges et al. ${ }^{7}$

The presence of silicone content in AH Plus creates high surface tension forces, making the sealer more difficult to spread resulting in more marginal gaps.

$\mathrm{AH}$ Plus is considered as a gold standard as it has better penetration into micro-irregularities because of its creep capacity and long setting time, which increase the mechanical interlocking between the sealer and the root dentin. ${ }^{8}$ Moreover, it has low solubility and small expansion while setting and bind to root dentin through adamantine.

Gutta-percha is the most commonly used core material and offers the advantages such as inertness, bio-compatibility, less technique sensitivity, ease of manipulation, and reinforces the root canal system. The major drawback of gutta-percha is lack of inherent bonding to the root dentin and it can be balanced by using a root canal sealer to enhance the adaptation to root canal wall. ${ }^{9}$ 
Table 2: One-way ANOVA. The results of the one-way ANOVA are given below

\begin{tabular}{|c|c|c|c|c|c|c|}
\hline & & Sum of squares & $d f$ & Mean square & $F$ & Sig. \\
\hline \multirow[t]{3}{*}{ Apical } & Between groups & 25178.667 & 2 & 12589.334 & 11.047 & 0.000 \\
\hline & within groups & 27351.954 & 24 & 1139.665 & & \\
\hline & Total & 52530.621 & 26 & & & \\
\hline \multirow[t]{3}{*}{ Middle } & Between groups & 34381.428 & 2 & 17190.714 & 13.467 & 0.000 \\
\hline & within groups & 30635.184 & 24 & 1276.466 & & \\
\hline & Total & 65016.612 & 26 & & & \\
\hline \multirow[t]{3}{*}{ Cervical } & Between groups & 127347.462 & 2 & 63673.731 & 60.995 & 0.000 \\
\hline & Within groups & 25054.173 & 24 & 1043.924 & & \\
\hline & Total & 152401.635 & 26 & & & \\
\hline
\end{tabular}

Table 3: Post hoc tests. As there is a significant difference, pairwise tests are conducted

\begin{tabular}{|c|c|c|c|c|c|}
\hline & (I) Material & (J) Material & Mean difference (I-J) & Std. error & Sig. \\
\hline \multirow[t]{6}{*}{ Apical } & AH Plus & BioRoot RCS & -24.522 & 15.914 & 0.136 \\
\hline & & Sealapex & 48.939 & 15.914 & 0.005 \\
\hline & BioRoot RCS & AH lus & 24.522 & 15.914 & 0.136 \\
\hline & & Sealapex & 73.461 & 15.914 & 0.000 \\
\hline & Sealapex & AH Plus & -48.939 & 15.914 & 0.005 \\
\hline & & BioRoot RCS & -73.461 & 15.914 & 0.000 \\
\hline \multirow[t]{6}{*}{ Middle } & AH Plus & BioRoot RCS & 79.652 & 16.842 & 0.000 \\
\hline & & Sealapex & 71.001 & 16.842 & 0.000 \\
\hline & BioRoot RCS & AH Plus & -79.652 & 16.842 & 0.000 \\
\hline & & Sealapex & -8.651 & 16.842 & 0.612 \\
\hline & Sealapex & AH Plus & -71.001 & 16.842 & 0.000 \\
\hline & & BioRoot RCS & 8.651 & 16.842 & 0.612 \\
\hline \multirow[t]{6}{*}{ Cervical } & AH Plus & BioRoot RCS & 167.924 & 15.231 & 0.000 \\
\hline & & Sealapex & 75.267 & 15.231 & 0.000 \\
\hline & BioRoot RCS & AH Plus & -167.924 & 15.231 & 0.000 \\
\hline & & Sealapex & -92.658 & 15.231 & 0.000 \\
\hline & Sealapex & AH Plus & -75.267 & 15.231 & 0.000 \\
\hline & & BioRoot RCS & 92.658 & 15.231 & 0.000 \\
\hline
\end{tabular}

Table 4: Descriptive statistics. Gap formation

\begin{tabular}{llrlll}
\hline & & $N$ & Mean & Std. deviation & Std. error \\
\hline Apical & AH Plus & 9 & 5.367 & 1.626 & 0.542 \\
& BioRoot RCS & 9 & 1.788 & 1.075 & 0.358 \\
& Sealapex & 9 & 5.390 & 1.188 & 0.396 \\
Middle & Total & 27 & 4.181 & 2.140 & 0.412 \\
& AH Plus & 9 & 3.324 & 1.068 & 0.356 \\
& BioRoot RCS & 9 & 1.752 & 0.796 & 0.265 \\
& Sealapex & 9 & 3.984 & 1.753 & 0.584 \\
Cervical & Total & 27 & 3.021 & 1.550 & 0.298 \\
& AH Plus & 9 & 2.592 & 1.142 & 0.381 \\
& BioRoot RCS & 9 & 2.051 & 1.621 & 0.540 \\
& Sealapex & 9 & 4.431 & 0.963 & 0.321 \\
\end{tabular}

According to Grossman, an ideal endodontic sealer should have a good adaptation to the root dentin and core filling material, good rheological behavior, adequate lubricant action, least solubility, high antibacterial activity; should be easy to manipulate; and should possess adequate dimensional stability. ${ }^{10}$ The discrepancies between the core material and the root dentin are the zone of action of endodontic sealers, they seals of areas inaccessible to the instruments and irregularities ensuring between the root dentin and the core material. The selection of sealers depends upon the analysis of various factors.

The flow of sealer is a major factor that aids in improving the adhesion and adaptation to the dentin which indirectly improves 
Table 5: One-way ANOVA. The results of the one-way ANOVA are given below

\begin{tabular}{|c|c|c|c|c|c|c|}
\hline & & Sum of squares & $d f$ & Mean square & $F$ & Sig. \\
\hline \multirow[t]{3}{*}{ Apical } & Between groups & 25178.667 & 2 & 12589.334 & 11.047 & 0.000 \\
\hline & Within groups & 27351.954 & 24 & 1139.665 & & \\
\hline & Total & 52530.621 & 26 & & & \\
\hline \multirow[t]{3}{*}{ Middle } & Between groups & 34381.428 & 2 & 17190.714 & 13.467 & 0.000 \\
\hline & Within groups & 30635.184 & 24 & 1276.466 & & \\
\hline & Total & 65016.612 & 26 & & & \\
\hline \multirow[t]{3}{*}{ Cervical } & Between groups & 127347.462 & 2 & 63673.731 & 60.995 & 0.000 \\
\hline & Within groups & 25054.173 & 24 & 1043.924 & & \\
\hline & Total & 152401.635 & 26 & & & \\
\hline
\end{tabular}

Table 6: Post hoc tests. As there is significant difference, pairwise tests are conducted

\begin{tabular}{|c|c|c|c|c|c|}
\hline & (I) Material & (J) Material & $\begin{array}{l}\text { Mean } \\
\text { difference }(I-J)\end{array}$ & $\begin{array}{l}\text { Std. } \\
\text { error }\end{array}$ & Sig. \\
\hline \multirow[t]{6}{*}{ Apical } & \multirow[t]{2}{*}{ AH Plus } & BioRoot RCS & 3.579 & 0.621 & 0.000 \\
\hline & & Sealapex & -0.023 & 0.621 & 0.970 \\
\hline & \multirow[t]{2}{*}{ BioRoot RCS } & AH Plus & -3.579 & 0.621 & 0.000 \\
\hline & & Sealapex & -3.602 & 0.621 & 0.000 \\
\hline & \multirow[t]{2}{*}{ Sealapex } & AH Plus & 0.023 & 0.621 & 0.970 \\
\hline & & BioRoot RCS & 3.602 & 0.621 & 0.000 \\
\hline \multirow[t]{6}{*}{ Middle } & \multirow[t]{2}{*}{ AH Plus } & BioRoot RCS & 2.234 & 0.599 & 0.001 \\
\hline & & Sealapex & 0.662 & 0.599 & 0.280 \\
\hline & \multirow[t]{2}{*}{ BioRoot RCS } & AH Plus & -2.234 & 0.599 & 0.001 \\
\hline & & Sealapex & -1.572 & 0.599 & 0.015 \\
\hline & \multirow[t]{2}{*}{ Sealapex } & AH Plus & -0.662 & 0.599 & 0.280 \\
\hline & & BioRoot RCS & 1.572 & 0.599 & 0.015 \\
\hline \multirow[t]{6}{*}{ Cervical } & \multirow[t]{2}{*}{ AH Plus } & BioRoot RCS & -2.381 & 0.600 & 0.001 \\
\hline & & Sealapex & -0.541 & 0.600 & 0.376 \\
\hline & \multirow[t]{2}{*}{ BioRoot RCS } & AH Plus & 2.381 & 0.600 & 0.001 \\
\hline & & Sealapex & 1.840 & 0.600 & 0.005 \\
\hline & \multirow[t]{2}{*}{ Sealapex } & AH Plus & 0.541 & 0.600 & 0.376 \\
\hline & & BioRoot RCS & -1.840 & 0.600 & 0.005 \\
\hline
\end{tabular}

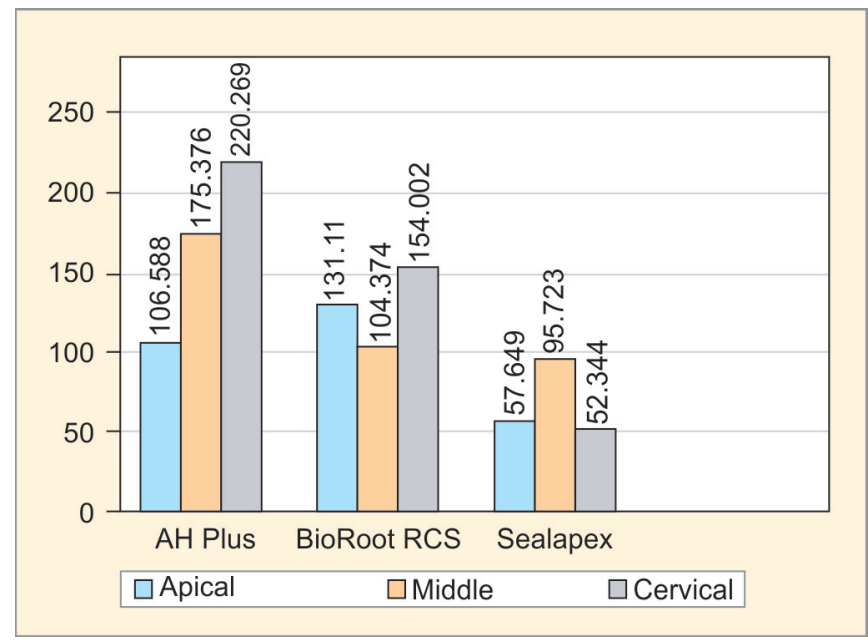

Fig. 10: Graphical representation—sealer penetrability (micrometers)

the stability of root filling. ${ }^{11}$ The penetration of root canal sealers depends on the diameter and the density of the dentinal tubules.

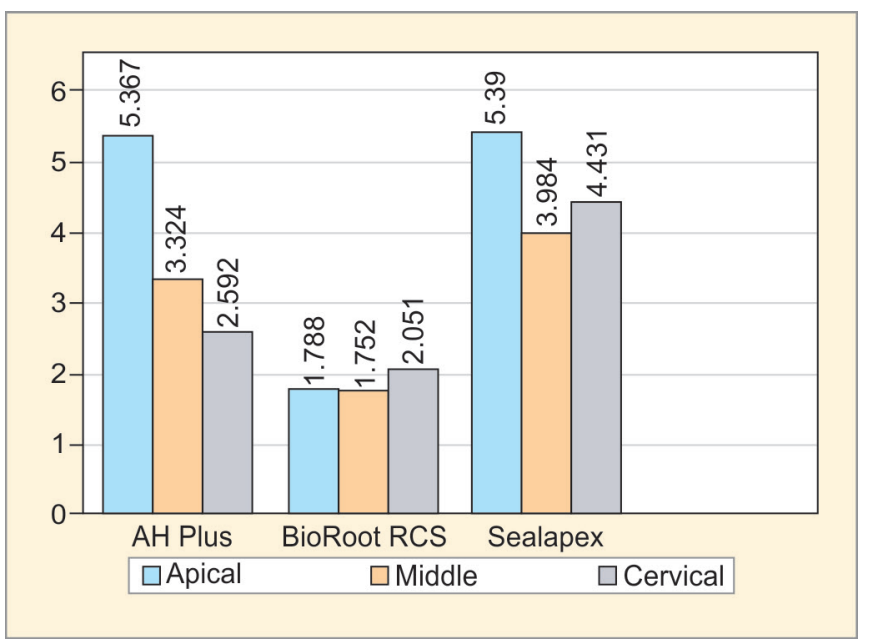

Fig. 11: Graphical representation—gap formation (micrometers)

In addition the surface activity of the sealers, contact angle formed between the sealer and the dentin, the obturation technique employed for root filling, and the sectioning method involved in the sample preparation play a key role in the sealer penetration and the gap formation. ${ }^{12}$

The diameter and the density of the dentinal tubules are more at the coronal and the middle third of the root canal system whereas minimal at the apical third, this factor plays a major role in sealer penetration. ${ }^{13}$ According to Boyde, a smear layer is an organic matter trapped within trans located inorganic dentine and is formed during instrumentation which is composed of organic and inorganic substances that include fragments of odontoblastic processes, microorganisms, and necrotic materials. ${ }^{14}$ A smear layer plays a major role in the penetration of root canal sealers, especially in the apical third. Removal of the smear layer not only improves the sealing ability of sealers but also increases the bond strength to dentinal walls, and reduces bacterial penetration and is removed using various demineralizing agents. ${ }^{15}$ Viscosity of the sealers is indirectly proportional to the penetration, higher the viscosity, lower the penetration which also depends on the composition of the sealer.

The chemical nature of sealers plays a major role in the sealer penetration; hydrophilic sealers penetrate deeper than hydrophobic sealers. ${ }^{16}$ Ideally, obturation with the least void and gaps is the major desirable outcome of the endodontic filling, which depends on the good surface adaptation and less shrinkage of sealer between the core material and the root dentin. ${ }^{17}$ 
Many studies have been evaluated to assess the sealing ability of the endodontic sealers through various methods such as dye penetration method, electrical methods, fluid filtration technique, radioisotope tracing, and scanning electron microscopy. ${ }^{18}$ In this study, a scanning electron microscope was utilized to estimate the mean penetration of root canal sealers. The advantage of using SEM over various sealing methods is that in SEM, the defects at the submicron level can be observed at required magnification and a final evaluation can be done by preserving microphotographs. ${ }^{19}$

Conventional zinc oxide eugenol-based sealers lack adequate penetration which leads to the modification in the sealer composition. ${ }^{20}$ In a quest for the search of newer materials in this direction, sealers based on adhesive principles are gaining popularity because of good retention by micromechanical bonding but the shrinkage associated with setting reaction is a major problem for the resin-based sealers. ${ }^{21}$ The AH Plus is available as a two-paste system which contains epoxide as a base and amine as a catalyst. The epoxide paste has diepoxide calcium tungstate zirconium oxide aerosil pigment; amine paste has 1 adamantane amine $N, N^{\prime}$-dibenzyl-5-oxa-nonandiamine-1,9 tricyclodecane (TCD)-diamine calcium tungstate zirconium oxide, aerosil silicone oil AH Plus has good biocompatibility, tissue tolerance, long-term dimensional stability, and sealing ability but silicone oil content of $\mathrm{AH}$ Plus increases surface tension, thereby shrinkage occurs at the sealer-dentin interface. ${ }^{22}$

Recently, calcium silicate-based sealers have been introduced into the market which denatures the collagen present in the dentin providing that a "mineral infiltrated zone" is found to have better penetration and dimensional stability. ${ }^{22}$

\section{Conclusion}

- Epoxy resin-based AH Plus sealer revealed better penetrability

- Minimum gap formation was observed for the bioceramic sealer

- Better penetration for epoxy resin-based and calcium hydroxidebased-sealer was revealed at the coronal third than the middle third

- Higher penetration of the bioceramic sealer was revealed at the apical third

\section{References}

1. Lee KW, Williams MC, et al. Adhesion of endodontic sealers to dentin and gutta-percha. J Endod 2002;28:684-688. DOI: 10.1097/00004770200210000-00002.

2. Gettleman $\mathrm{BH}, \mathrm{Messer} \mathrm{HH}$, et al. Adhesion of sealer cements to dentin with and without the smear layer. J Endod 1991;17:15-20. DOI: 10.1016/ S0099-2399(07)80155-5.

3. Al-Haddad A, Che Ab Aziz ZA. Bioceramic-based root canal sealers: a review. Int J Biomater 2016;2016:9753210. DOI: 10.1155/2016/9753210.

4. Rached-Junior FJ, Sousa-Neto MD, et al. Impact of remaining zinc oxide-eugenol-based sealer on the bond strength of a resinous sealer to dentine after root canal retreatment. Int Endod J 2014 May;47(5):463-469. DOI: 10.1111/iej.12170.

5. Branstetter J, von Fraunhofer JA. The physical properties and sealing action of endodontic sealer cements: a review of the literature. J Endod 1982;8:312-316. DOI: 10.1016/S0099-2399(82)80280-X.

6. Kossev D, Stefanov V. Ceramics-based sealers as new alternative to currently used endodontic sealers. Roots 2009;1:42-48.

7. Borges RP, Sousa-Neto MD, et al. Changes in the surface of four calcium silicate-containing endodontic materials and an epoxy resin-based sealer after a solubility test. Int Endod J 2012 May;45(5): 419-428. DOI: 10.1111/j.1365-2591.2011.01992.x.

8. Prakash R, Gopikrishna V, et al. Gutta-percha-an untold story. Endodontology 2005;17(2):32-36.

9. Zhou HM, Shen $Y$, et al. Physical properties of 5 root canal sealers. J Endod 2013 Oct 1;39(10):1281-1286. DOI: 10.1016/j.joen.2013.06.012.

10. Lim ES, Park YB, et al. Physical properties and biocompatibility of an injectable calcium-silicate-based root canal sealer: an in vitro and in vivo study. BMC Oral Health 2015 Dec;15(1):129. DOI: 10.1186/ s12903-015-0112-9.

11. Mamootil K, Messer HH. Penetration of dentinal tubules by endodontic sealer cements in extracted teeth and in vivo. Int Endod J 2007 Nov;40(11):873-881. DOI: 10.1111/j.1365-2591.2007.01307.x.

12. Lo Giudice G, Cutroneo G, et al. Dentin morphology of root canal surface: a quantitative evaluation based on a scanning electronic microscopy study. Biomed Res Int 2015;2015:164065. DOI: 10.1155/2015/164065.

13. Pashley DH, Michelich V, et al. Dentin permeability: Effects of smear layer removal. J Prosthet Dent 1981 Nov 1;46(5):531-537. DOI: 10.1016/0022-3913(81)90243-2.

14. Rouhani A, Ghoddusi J, et al. The sealing ability of resilon and guttapercha in severely curved root canals: an in vitro study. J Dent (Tehran) 2013 Mar;10(2):141.

15. Lacey S, Pitt Ford TR, et al. The effect of temperature on viscosity of root canal sealers. Int Endod J 2006 Nov;39(11):860-866. DOI: 10.1111/j.1365-2591.2006.01154.x.

16. Al-Haddad A, Ab Aziz C, et al. Bioceramic-based root canal sealers: a review. Int J Biomater 2016;2016:9753210. DOI: 10.1155/2016/ 9753210.

17. Schilder H. Filling root canals in three dimensions. J Endod $2006 \mathrm{Apr} 1$; 32(4):281-290. DOI: 10.1016/j.joen.2006.02.007.

18. Kalra M, lqbal K, et al. The effect of proanthocyanidins on the bond strength and durability of resin sealer to root dentine. Int Endod J 2013 Feb;46(2):169. DOI: 10.1111/j.1365-2591.2012.02106.x.

19. Kapoor V, Singh H, et al. Qualitative and Quantitative Comparative Evaluation of Sealing Ability of Guttaflow, Thermoplasticized Gutta Percha and Lateral Compaction for Root Canal Obturation: A Cohort, Controlled, Ex Vivo Study. Oral Health Dent Manag 2013;12(3):155-161.

20. Khader MA. An In Vitro Scanning Electron Microscopy Study to Evaluate the Dentinal Tubular Penetration Depth of Three Root Canal Sealers. J Int Oral Health 2016 Feb 1;8(2):191.

21. Elias I, Guimarães GO, et al. Apical sealing ability comparison between GuttaFlow and AH Plus: in vitro bacterial and dye leakage. J Health Sci Inst 2010;28(1):77-79.

22. Savariz A, González-Rodríguez MP, et al. Long-term sealing ability of GuttaFlow vs Ah Plus using different obturation techniques. Med Oral Patol Oral Cir Bucal 2010 Nov 1;15(6):e936-e941. DOI: 10.4317/ medoral.15.e936. 